\title{
Therapeutic Dietary Modifications Can Modify the Devastating Consequences of Cardio-Metabolic Syndrome (CMS): A Scientific Analysis
}

\author{
Mohammad Nazrul Islam* \\ Department of Unani Medicine,Hamdard University Bangladesh, Bangladesh
}

Submission: April 16, 2018; Published: July 18, 2018

*Corresponding author: Mohammad Nazrul Islam, Assistant Professor, Department of Unani Medicine; Hamdard University Bangladesh, Bangladesh,Tel: 008801732780912; Email: dr_sayemnazrul@yahoo.com

\begin{abstract}
Cardio-metabolic syndrome (CMS) or Syndrome $\mathrm{X}$ is a disease of modern civilization. It is assumed that physical inactivity, obesity, sedentary life style, stressful life, shifting and drifting of socioeconomic status, changing the dietary pattern and tendency to cultural fission and fusion are prime factors associated with development of CMS. It has long term and devastating consequences and ultimate leads to death, if untreated.So, early diagnosis and proper treatment are necessary to combat the disease. By developing information, education and communication system to mass communities, changing the dietary pattern, therapeutic life style and adopt the different strategies, policies and interventions can reduce the mortality and morbidity of the sequential disease.It is an attempt to amalgamate the different therapeutic dietary modification strategies, techniques and policies to combat the CMS.
\end{abstract}

\section{Introduction}

Cardio-metabolic syndrome or Syndrome $\mathrm{X}$ is a disease of modern civilization due to physical inactivity, obesity, sedentary life style, stressful life, shifting and drifting of socioeconomic status, changing the dietary pattern and tendency to cultural fission and fusion. The components of the syndrome are dysglycemia, raised blood pressure, elevated triglyceride (TG) levels; lower the high density lipoprotein (HDL-C)[1,2], central obesity and prothrombic state[3]. It is also associated with cancer, chronic kidney disease and death. It has been proved that therapeutic dietary modification can reduce the devastating consequences of cardio-metabolic syndrome (CMS).It was estimated that approximately 47 million Americans were in high risk of heart disease because they were enrolled by a complex conditions like obesity, impaired glucose metabolism, hypertension and lipid disorders[4].It is an attempt to amalgamate the different therapeutic dietary modification strategies, techniques and policies to combat the CMS.

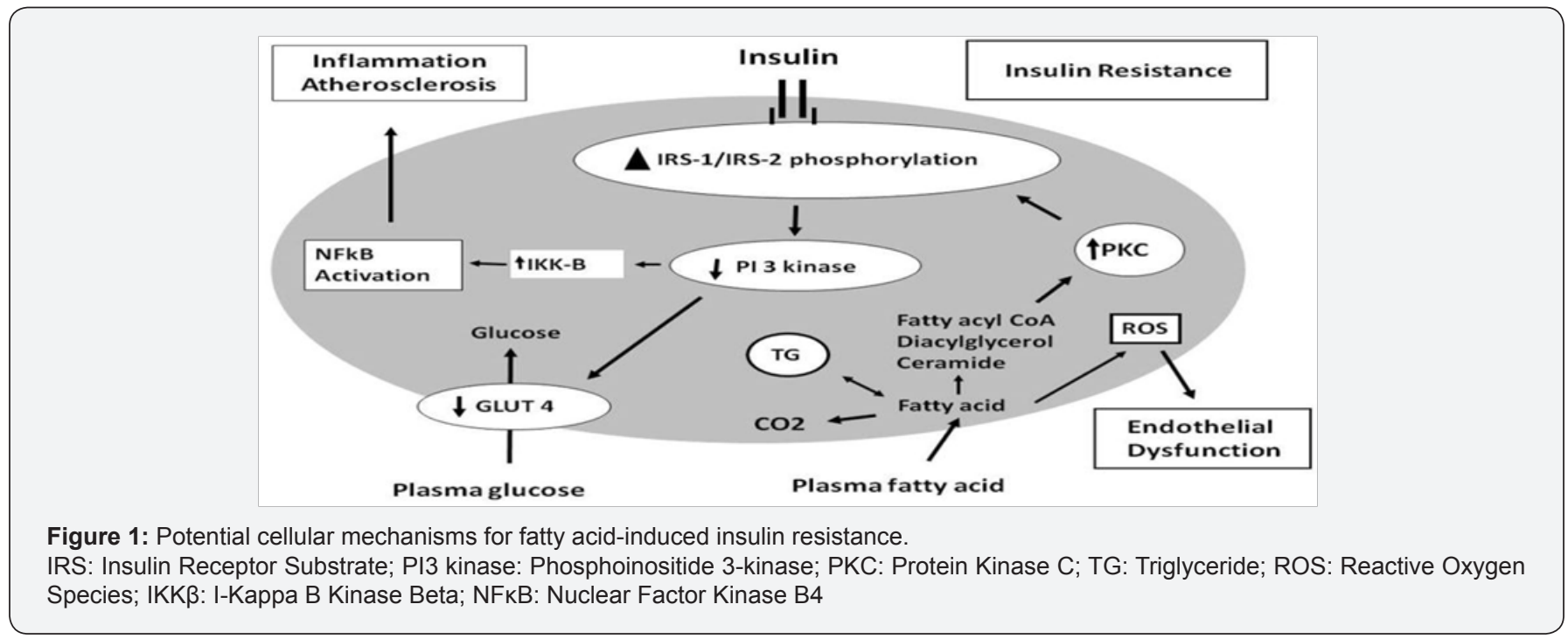

Curr Res Diabetes Obes J 8(1): CRDOJ.MS.ID.555726(2018). 


\section{Current Research in Diabetes \& Obesity Journal}

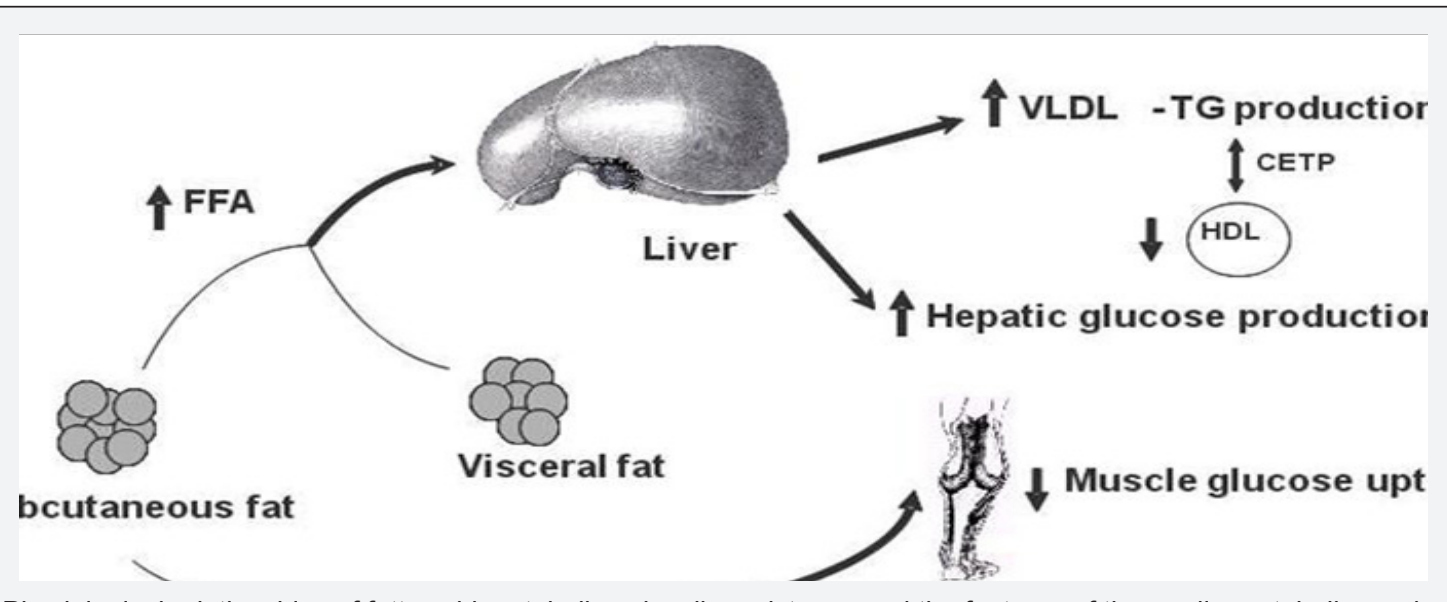

Figure 2: Physiological relationships of fatty acid metabolism, insulin resistance and the features of the cardio-metabolic syndrome. CETP: Cholesterol Ester Transfer Protein; VLDL: Very-Low Density Lipoprotein Triglyceride; HDL: High Density Lipoprotein

\section{Mechanism of Development of CMS}

(Figure $1 \& 2$ )

\section{Studies related to dietary pattern and cardio metabolic syndrome}

Different studies found that the patients with metabolic syndrome trends to increase two folds risk of cardiovascular disease (CVD) and 5 folds increase the risk of type 2 diabetes mellitus (T2DM). Lifestyle changes like weight loss, increased physical activity and dietary modifications have been shown significant improvement of the marker of metabolic syndrome. It has been observed that low carbohydrate diets aremore effective than low fat diets for resolving metabolic syndrome. It is recommended to reduce the consequences of Metabolic Syndrome by modification of diet such as carbohydrate diets $<7 \%$ of total calories; trans-fat $<1 \%$ of total calories, polyunsaturated fat up to $10 \%$ of total calories, monounsaturated fat up to $20 \%$ of total calories and fiber $20-30 \mathrm{~g} /$ day, proteinapproximately $15 \%$ of total calories, cholesterol $<200 \mathrm{mg} /$ day in total calories[5]. DASH (Dietary approaches to stop hypertension) dietary pattern emphasizes to consume more fruits, vegetables, low-fat dairy foods, whole grains, poultry, fish, nuts, seeds and legumes. Additionally, it is low in saturated fat, total fat, cholesterol, red meat, sweets, sugared beverages and refined grains. DASH was originally developed to manage or prevent high blood pressure[6]. Azadbakht et al. showed on clinical trial among the 116 men and women with MetS demonstrated that 6-months intervention with DASH diet significantly reduced body weight, waist circumference, triglyceride, systolic blood pressure, diastolic blood pressure, fasting blood sugar and also increased HDL-C (High density lipoprotein-Cholesterol) ultimately reduced the risk of the syndrome around $20 \%$. In a randomized crossover clinical trial showed that DASH diet is reducedcardio metabolic risks among the type 2 diabetic patients andsignificant improvements in insulin sensitivity[7]. The Mediterranean diet (MD) which was first introduced by Ancel Keys in 1960s. It isused to follow by people in the different bordering countries of the Mediterranean Sea including Greece, Spain, Southern Italy, Portugal and Turkey. This dietary pattern is characterized by daily consumption of non-refined cereals, vegetables (two or three servings per day), fruit (four to six servings per day), different olive oil products and nonfat or low-fat dairy products (one or two servings per day); weekly consumption of potatoes (four to five servings per week), fish (four to five servings per week),olives, pulses and nuts (more than four servings per week), more rarely poultry, eggs, and sweets (one to three servings per week), and monthly consumption of red meat and meat products(four or five servings per month with meals). Esposito et al. in a randomized clinical trial on 180 men and women for 24 month intervention with MD showed that prevalence of MetS was reduced by approximately $50 \%$. The reduction in the prevalence of MetS was owed to significantly decrease in waist circumference, blood pressure, plasma glucose, total cholesterol and triglyceride concentrations, and a significant increase in HDL in the intervention group.A recent systematic review and meta-analysis of 50 studies including both observational studies and randomized controlled trials reinforced the benefits of MD on improving the MetS and it reduce the risk of developing the syndrome by $31 \%$. Antioxidant and anti-inflammatory properties of the foods included in MD as well as high intake of vitamins and minerals reduce the incidence ofMetS. Recently, it is shown that 2 months intervention with MD effectively increases total dietary antioxidant intake and plasma total antioxidant capacity. Olive oil is one of main food items of MD which has been shown to reduce cardiovascular risk factors, such as lipid profiles, blood pressure, postprandial hyperlipidemia, endothelial dysfunction, oxidative stress and antithrombotic profiles[8]. Phenolic compounds in olive oil have also shown antioxidant and antiinflammatory properties that improve endothelial function[9]. Olive oil lowers NF-kB activation, thus leads to decrease in markers of inflammation (CRP, IL-6 and IL-8), oxidation and thrombosis[10]. Nuts are another highunsaturated fat food commonly consumed in the MD[11]. 
One study showed that forty-four healthy women and men (50-73 years, BMI 25-33, fasting glycaemia $\leq 6.1 \mathrm{mmol} / \mathrm{L}$ ) participated in a randomized crossover intervention comparing a multifunctional (active) diet (AD) with a control diet (CD). Each diet was consumed during 4 weeks with a 4 weeks washout period. Active Diet (AD) included the following functional concepts: low glycemic impact meals, antioxidant-rich foods, and oily fish as source of long-chain omega-3 fatty acids, viscous dietary fibers, soybean, whole barley kernel products, almonds, stanols and a probiotic strain (Lactobacillus plantarum Heal19/ DSM15313). AD promoted significant changes in total serum cholesterol $(-26 \pm 1 \%$ vs baseline; $\mathrm{P}<0.0001)$, LDL cholesterol $(-34 \pm 1 \% ; \mathrm{P}<0.0001)$, triglycerides $(-19 \pm 3 \% ; \mathrm{P}=0.0056), \mathrm{LDL} /$ HDL $(-27 \pm 2 \%$; $\mathrm{P}<0.0001)$, apo B/apoA1 $(-10 \pm 2 \%$; $<<0.0001)$, HbA1c $(-2 \pm 0.4 \% ; \mathrm{P}=0.0013)$, hs-CRP $(-29 \pm 9 \% ; \mathrm{P}=0.0497)$ and systolic blood pressure $(-8 \pm 1 \%, \mathrm{P}=0.0123)[12]$.Williams et al. in a crosssectional study demonstrated that a healthy balanced diet high in raw and salad vegetables, fruits, fish, pasta, rice and low in fried foods, sausages, fried fish, and potatoes was negatively associated with central obesity, fasting plasma glucose, and triacylglycerol and also positively associated with HDL-C[5]. Finally, scientific evidence suggested that reducing dietary carbohydrate is the prime approach for prevention or treatment of MetS. Increasing dietary protein as an approach to lowering dietary carbohydrates may be more effective than increasing fat.

\section{Clinical features of cardio-metabolic syndrome}
A. Dyslipidemia
B. Type 2Diabetes Mellitus
C. Polycystic ovary syndrome
D. Fatty liver resulting in inflammation and the potential for cirrhosis
E. Micro albuminuria
F. Obstructive sleep apnea
G. Increased risk of dementia with aging
H. Hypertension

According to the National Heart, Lung, and Blood Institute (NHLBI) and the American Heart

Association (AHA), any three of the following criterias in the same individual can be diagnosed

as metabolic syndrome are:

1. Abdominal obesity: a waist circumference of $102 \mathrm{~cm}$ (40in) or more in men and $88 \mathrm{~cm}$

(35 inches) or more in women. For Asian Americans, the cutoff values are $\geq 90 \mathrm{~cm}(35 \mathrm{in})$

in men or $\geq 80 \mathrm{~cm}$ (32in) in women.
2. Serum triglycerides $150 \mathrm{mg} / \mathrm{dl}$ or above.

3. HDL cholesterol $40 \mathrm{mg} / \mathrm{dl}$ or lower in men and $50 \mathrm{mg} / \mathrm{dl}$ or lower in women

4. Blood pressure of $130 / 85$ or more.

5. Fasting blood glucose of $100 \mathrm{mg} / \mathrm{dl}$ or above.

\section{Laboratory tests suggested for CMS}

1. Thyroid profile

2. Liver Function Tests

3. Lipid profile (Fasting)

4. $\quad$ CReactive Protein

5. Lipoprotein(a), apolipoprotein-B100(Apo)

6. Homocysteine

7. Hemoglobin-A1C levels

8. Uric acid

9. Microalbuminuria (Albumin/creatinine ratio)

10. Electrocardiography (rest/stress ECG)

11. Ultrasonography (vascular or rest/stress echocardiography) but fatty liver can be confirmed by nuclear magnetic resonance spectroscopy

12. Stress single-photon emission computed tomography (SPECT)

13. Cardiac positron emission tomography (PET)

14. Adipokine

15. Plasminogen Activator Inhibitor-1

16. Plasma glucose

\section{Management of CMS}

\section{Phyto-therapy for management of CMS}

Resveratrol $\left(3,5,4^{\prime}\right.$-trihydroxystilbene found in grapes and other plant species): Animal studies showed that resveratrolcan reduceabnormal blood fat (cholesterol and triglycerides) andblood pressure and fightagainst inflammation[13].

Alpha lipoic acid (spinach and broccoli): An antioxidant that helps burn glucose to power the heart, brain and all other organs. It thus lowers glucose and insulin levels, reduces insulin resistance and slows the aging process[14].

Gymnemasylvestre:TreatmentwithDAGA(deacylgymnemic acid)resulted in a significant decrease in insulin resistance accompanied with a decrease in systolic blood pressure and improved glucose and lipid profile without decreasing body weight in a rat model of metabolic syndrome[15]. 


\section{Current Research in Diabetes \& Obesity Journal}

Silymarin (Standardized): An antioxidant flavonoid from the herb milk thistle, silymarin lowers/stabilizes blood glucose levels and protects the liver, the most important tissue involved in insulin utilization[16]

Cinnamontree: Bark (3gm) of the Cinnamomumzeylanicum (Cinnamon)-have shown reducepost prandial serum insulin and increased GLP-1 concentration without significantly affecting blood glucose in human[17].

Wheat: Fibers (24gm/day) of Triticumaestivum have shown increased short chain Fatty acid production and glucagon like peptide-1 secretion in human model for many days[18].

Gardenia: Fruit of the Gardenia jesminoides (geniposide) prevents the oxidative stress induced neuron apoptosis and improved glucose stimulated insulin secretion by activating glucagon like peptide 1 receptor in INS-1cell[19].

CoQ10(Ubiquinol): CoQ10 is a powerful antioxidant that modulates blood pressure apparently by reducing resistance to blood flow. It also is generally important for cardiovascular health. The body uses CoQ10 to convert food into energy and several trials have reported that supplementing with CoQ10 for 2.5-4 months significantly reduces hypertension[20].

Fish oil (EPA/DHA): EPA and DHA are key omega-3 essential fatty acids (EFAs) in the oil of fatty fish such as anchovies, sardines, salmon, herring, white albacore tuna, haddock and mackerel. The Journal of the American College of Nutrition 2002 has reported that EPA and DHA "may play an important role in the prevention and treatment of coronary artery disease, hypertension and other inflammatory disorders[21-23].

\section{Conclusion}

Therapeutic dietary modification and life style change techniques can reduce the consequences of cardio metabolic syndrome. Though it is very difficult to change the dietary habit within in single intervention but continuous motivation can change the pattern of diet and life style.By modifying the dietary pattern, increasing the physical activities, avoiding sedentary life style and changing the life style can combat the morbidity and mortality of MetS.

\section{References}

1. Expert Panel on Detection, Evaluation, and Treatment of High Blood Cholesterol in Adults (2001) Executive summary of the third report of the national cholesterol education program (NCEP) expert panel on detection, evaluation, and treatment of high blood cholesterol in adults (Adult Treatment Panel III). JAMA 285(19): 2486-2497.

2. NCEP, Adult Treatment Panel III (2002) Third report of the national cholesterol education program (NCEP) expert panel on detection, evaluation, and treatment of high blood cholesterol in adults (Adult Treatment Panel III) final report. Circulation 106(25): 3143-3421.

3. Grundy SM, Cleeman JI, Daniels SR, Donato KA, Eckel RH, et al. (2005) Diagnosis and management of the metabolic syndrome: an American Heart Association/National Heart, Lung, and Blood Institute Scientific Statement. Circulation 112(17): 2735-2752.
4. Shulman GI (2000) Cellular mechanisms of insulin resistance. J Clin Invest 106: 171-176.

5. Ebrahimof S, Mirmiran P (2013) Nutritional approaches for prevention and treatment of metabolic syndrome in adults. J Paramed Sci 4(2): $123-134$.

6. Crystal C, Tyson, Chinazo N, Lin P, Svetkey LP (2012) The Dietary Approaches to Stop Hypertension (DASH) eating pattern in special populations. Curr Hypertens Rep 14(5): 388-396.

7. (2013) Journal of paramedical sciences. Spring 4(2).

8. Pere Jimenez F, Alvarez de Cienfuegos G, Badimon L, Barja G, Battino $\mathrm{M}$, et al. (2005) International conference on the healthy effect of virgin olive oil. Eur J Clin Invest 35(7): 421-424.

9. Riccioni G, Speranza L, Pesce M, Cusenza S, D’Orazio N, et al. (2012) Novel phytonutrient contributors to antioxidant protection against cardiovascular disease. Nutrition 28(6): 605-610.

10. Tuck KL, Hayball PJ (2002) Major phenolic compounds in olive oil: metabolism and health effects. J Nutr Biochem 13(11): 636-644.

11. Visioli F (2012) Olive oil phenolics: where do we stand? Where should we go? Journal of the science of food and agriculture 92(10): 20172019.

12. Lopez Miranda J, Perez Jimenez F, Ros E, De Caterina R, Badimon L et al. (2010) Olive oil and health: summary of the II international conference on olive oil and health consensus report, Jaén and Córdoba (Spain) 2008. Nutr Metab Cardiovasc Dis 20(4): 284-294.

13. Bes Rastrollo M, Sabate J, Gomez Gracia E, Alonso A, Martinez JA, et al (2007) Nut consumption and weight gain in a Mediterranean cohort: The SUN study. Obesity 15(1): 107-116

14. Nilsson A, Tovar J, Johansson M, Radeborg K, Björck I (2013) A diet based on multiple functional concepts improves cognitive performance in healthy subjects. Nutr Metab 10: 49.

15. Andrew BA (2014) Resveratrol use in metabolic syndrome. Metab Syndr Relat Disord 12(10): 493-495.

16. Gomes MB, Negrato CA (2014) Alpha-lipoic acid as a pleiotropic compound with potential therapeutic use in diabetes and other chronic diseases. Diabetol Metab Syndr 6(1): 80.

17. Bhansali S, Shafiq N, Pandhi P, Singh AP, Singh I, et al. (2013) Effect of a deacylgymnemic acid on glucose homeostasis \& metabolic parameters in a rat model of metabolic syndrome. Indian J Med Res 137(6): 11741179.

18. Karimi G, Vahabzadeh M, Lari P, Rashedinia M, Moshiri M (2011) Silymarin, a promising pharmacological agent for treatment of diseases. Iran J Basic Med Sci 14(4): 308-317.

19. Hlebowicz J, Hlebowicz A, Lindstedt S, Björgell O, Höglund P, et al. (2009) Effects of 1 and $3 g$ cinnamon on gastric emptying, satiety, and postprandial blood glucose, insulin, glucose-dependent insulinotropic polypeptide, glucagon-like peptide 1 , and ghrelin concentrations in healthy subjects. Am J Clin Nutr 89(3): 815-821.

20. Freeland KR, Wilson C, Wolever TM (2010) Adaptation of colonic fermentation and glucagon-like peptide-1 secretion with increased wheat fibre intake for 1 year in hyperinsulinaemic human subjects. $\mathrm{Br}$ J Nutr 103(1): 82-90.

21. Liu J, Yin F, Xiao H, Guo L, Gao X (2012) Glucagon-like peptide 1 receptor plays an essential role in geniposide attenuating lipotoxicityinduced $\beta$-cell apoptosis. Toxicol in Vitro 26(7): 1093-1097.

22. Natural ways to reverse syndrome $X$, The silent killer.

23. https://www.ncbi.nlm.nih.gov/books/NBK279095 
(C) This work is licensed under Creative

BY Commons Attribution 4.0 Licens
DOI: $10.19080 /$ CRDOJ.2018.08.555726

\section{Your next submission with Juniper Publishers} will reach you the below assets

- Quality Editorial service

- Swift Peer Review

- Reprints availability

- E-prints Service

- Manuscript Podcast for convenient understanding

- Global attainment for your research

- Manuscript accessibility in different formats

( Pdf, E-pub, Full Text, Audio)

- Unceasing customer service

Track the below URL for one-step submission https://juniperpublishers.com/online-submission.php 